\title{
Diverse structures of mixed-metal oxides containing rare earths and their magnetic properties
}

\author{
Yukio HINATSU ${ }^{\dagger}$ \\ Division of Chemistry, Hokkaido University, Sapporo 060-0810, Japan
}

\begin{abstract}
The solid state chemistry of mixed-metal oxides containing rare earths ( $4 f$ elements) and $4 d$ or $5 d$ transition elements has attracted a great deal of interest, because these materials adopt a diverse range of structures and show a wide range of electronic properties due to $4 f$ and $4 d$ (or $5 d$ ) electrons. We have focused our attention on the structural chemistry and magnetic properties of perovskite-type oxides with the general formula $A_{n} L_{n} M_{n-1} O_{3 n}(A=C a, S r, B a ; L n=$ rare earths; $M=R u, I r ; n=1-4)$. Their structures are controlled by changing the ratio of the $\mathrm{Ln}$ and $\mathrm{M}$ ions, and peculiar magnetic properties and magnetic structures have been investigated by magnetic susceptibility, specific heat and neutron diffraction measurements.
\end{abstract}

(C2015 The Ceramic Society of Japan. All rights reserved.

Key-words : Magnetic properties, Perovskite, Rare earth, Magnetic structure, Ruthenium, Iridium

[Received April 6, 2015; Accepted July 7, 2015]

\section{Introduction}

It is well known that the most stable oxidation state of rare earth ions is trivalent, and the electron configuration of $\mathrm{Ln}^{3+}$ ions is $[\mathrm{Xe}] 4 \mathrm{f}^{\mathrm{n}}([\mathrm{Xe}]$ : xenon electronic core). The magnetic properties of the rare earth ions are fascinating for the reason of their systematic variety and intelligible complexity. They are highly localized electrons, and the shielding by the surrounding $5 \mathrm{~s}$ and $5 \mathrm{p}$ electrons in the outer shell makes the magnetic interactions between $4 \mathrm{f}$ electrons in the condensed matter very weak, compared with those between $d$ electrons. In fact, many of the rare earth oxides order magnetically when the temperature is decreased down to below $4 \mathrm{~K}$.

One of the most challenging problems in the modern chemistry of rare earth compounds is to find a compound in which strong magnetic super-exchange interactions between $4 \mathrm{f}$ electrons exist, which give rise to a long-range magnetic ordering at relatively high temperatures, and to elucidate their mechanism.

We have been focusing our attention on the crystal structures of the perovskite-type compounds containing rare earth ions. The rare earth ion is relatively large and tends to adopt a high coordination number. Therefore, the rare earth ion usually sits at the A site of the perovskite-type oxides $\mathrm{ABO}_{3}$. Not the A site ions but the $\mathrm{B}$ site ions normally determine the physical properties of the perovskites. ${ }^{1)}$

In this review article, we describe the preparation and structures of $\mathrm{ALnO}_{3}(\mathrm{~A}=$ alkaline earth elements; $\mathrm{Ln}=$ rare earths $)$ and $\mathrm{A}_{n} \mathrm{LnM}_{n-1} \mathrm{O}_{3 n}(\mathrm{n}=2-4)$ in which the rare earth elements are situated at the B-site of the perovskite-type oxides. Through magnetic susceptibility, specific heat, and neutron diffraction measurements, their magnetic properties have been studied.

\section{2. $\mathrm{ALnO}_{3}(\mathrm{~A}=\mathrm{Ba}, \mathrm{Sr} ; \mathrm{Ln}=\mathrm{Pr}, \mathrm{Tb})$}

Among seventeen rare earth elements, cerium, praseodymium and terbium have the tetravalent state in addition to the trivalent state. The electron configuration of $\mathrm{Pr}^{4+}$ and $\mathrm{Tb}^{4+}$ ions are

\rceil Corresponding author: Y. Hinatsu; E-mail: hinatsu@ sci.hokudai. ac.jp
$[\mathrm{Xe}] 4 \mathrm{f}^{1}$ and $[\mathrm{Xe}] 4 \mathrm{f}^{7}$ (half-filled $4 \mathrm{f}$ shell), respectively. These electronic configurations simplify the analysis of the electronic properties of $4 \mathrm{f}$ electrons in solids, and it is easy to compare the experimental results with theoretical calculations.

Since the ionic radius of tetravalent rare earths is considerably smaller than that of the corresponding trivalent rare earths, $\mathrm{Pr}^{4+}$ and $\mathrm{Tb}^{4+}$ ions should be situated at the B-site of the perovskite. Under flowing oxygen atmosphere, $\mathrm{BaPrO}_{3}, \mathrm{BaTbO}_{3}, \mathrm{SrPrO}_{3}$ and $\mathrm{SrTbO}_{3}$ could be prepared. They are crystallized orthorhombically (space group: Pnma). ${ }^{2-5)}$ Electron paramagnetic resonance measurements clearly showed that the oxidation state of Pr and $\mathrm{Tb}$ is in the tetravalent state. ${ }^{6), 7)}$ Magnetic susceptibility, specific heat and neutron diffraction measurements show that $\mathrm{BaPrO}_{3}$, $\mathrm{SrTbO}_{3}$ and $\mathrm{BaTbO}_{3}$ order magnetically at relatively high temperatures, i.e., 11.7, 32.0, and 33.4 K, respectively. ${ }^{5), 7), 8)}$ Figure 1 shows the temperature dependence of the magnetic susceptibility for $\mathrm{SrTbO}_{3}$ and $\mathrm{BaTbO}_{3}$. X-ray diffraction measurements show that $\mathrm{Pr}-\mathrm{O}-\mathrm{Pr}(\mathrm{Tb}-\mathrm{O}-\mathrm{Tb})$ is almost linearly aligned in their structures, which results in the strong magnetic super-exchange interaction via oxygen atoms. For the case of $\mathrm{SrPrO}_{3}$, the bond angle of $\mathrm{Pr}-\mathrm{O}-\mathrm{Pr}$ is $140^{\circ}$ and no magnetic ordering has been observed down to $1.8 \mathrm{~K}^{4)}$

Magnetic structures for any of these compounds is the G-type one from their neutron diffraction measurements. Figure 2 shows the magnetic structure of $\mathrm{SrTbO}_{3}$ measured at $2.0 \mathrm{~K}$.

\section{Double perovskites $\mathrm{A}_{2} \mathrm{LnMO}_{6}$ $(\mathrm{A}=\mathrm{Ba}, \mathrm{Sr}, \mathrm{Ca} ; \mathrm{M}=\mathrm{Ru})$}

The perovskites have the flexibility of chemical composition and the possibility of combination of many kinds of ions. By selecting large alkaline earth elements such as $\mathrm{Sr}$ and $\mathrm{Ba}$ at the $\mathrm{A}$ site atoms in the $\mathrm{ABO}_{3}$, one can accommodate the rare earth (Ln) with smaller transition elements (M) at the 6-coordinate B sites. Since the size of the $L n$ and $M$ cations are sufficiently different, they are regularly ordered over the six-coordinate $B$ sites.

Since highly oxidized cations from the second or third transition series sometimes show quite unusual magnetic behavior, many studies have been performed on the preparation and magnetic properties of double perovskite oxides containing both rare 

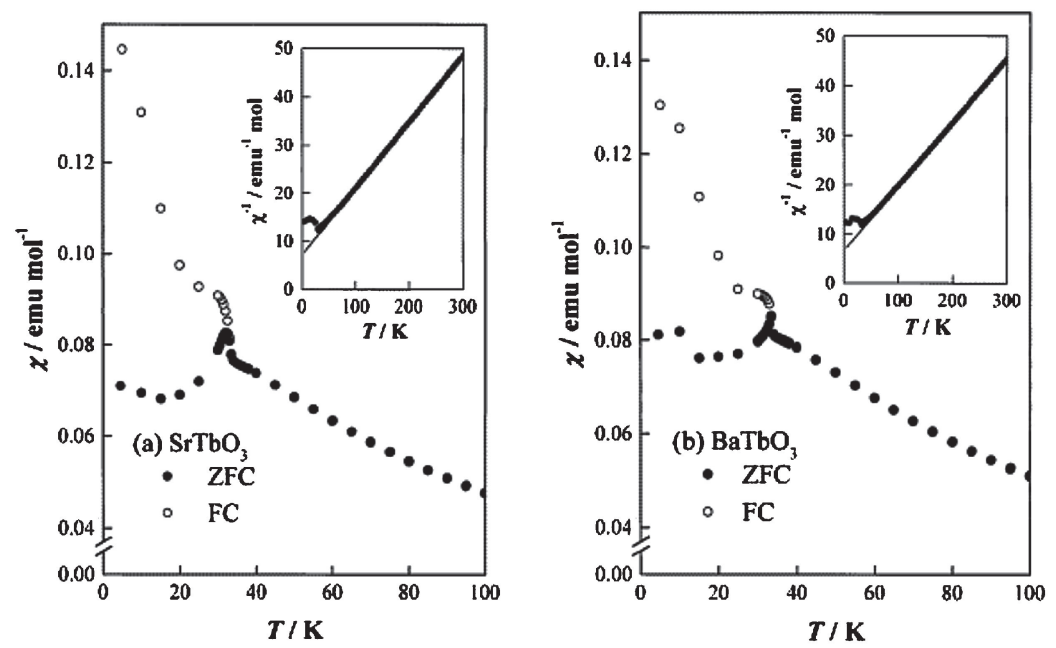

Fig. 1. Temperature dependence of the magnetic susceptibility for (a) $\mathrm{SrTbO}_{3}$ and (b) $\mathrm{BaTbO}_{3}$. The inset shows the temperature dependence of the reciprocal ZFC susceptibility and the Curie-Weiss fitting.

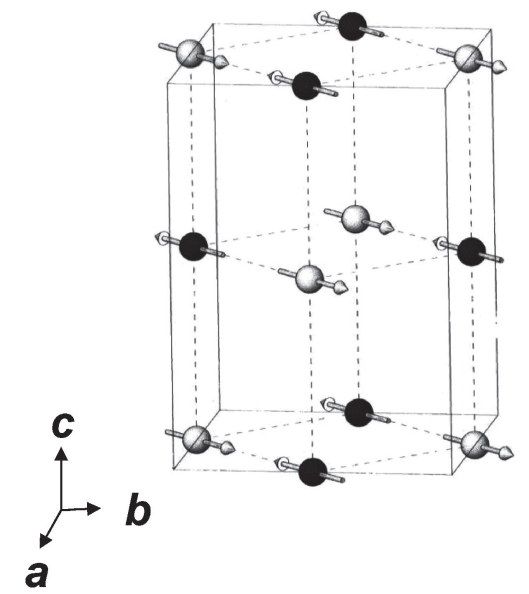

Fig. 2. Magnetic structure of $\mathrm{SrTbO}_{3}$ measured at $2.0 \mathrm{~K}$

earth and such transition metals, $\mathrm{A}_{2} \mathrm{LnMO}_{6}(\mathrm{~A}=\mathrm{Sr}, \mathrm{Ba} ; \mathrm{Ln}=$ rare earths; $\mathrm{M}=\mathrm{Ru}$, Os, Ir, Re). ${ }^{9-26)}$ Among them, magnetic properties of pentavalent ruthenium-containing oxides have aroused a great deal of interest, because the $\mathrm{Ru}^{5+}$ ion has the largest possible spin $(S=3 / 2)$.

The Rietveld analyses of their X-ray diffraction patterns for $\mathrm{A}_{2} \mathrm{LnRuO}_{6}$ compounds show that for $\mathrm{A}=\mathrm{Ba}$, the compounds with large rare earths $(\mathrm{Ln}=\mathrm{Pr}, \mathrm{Nd})$ adopt a monoclinic unit cell (space group $\left.\mathrm{P} 2{ }_{1} / \mathrm{n}\right)$ and those with small rare earths $(\mathrm{Ln}=\mathrm{Sm}-$ $\mathrm{Lu}$ ) adopt a cubic unit cell (space group Fm-3m). Figure 3 shows their schematic structures. For $\mathrm{A}=\mathrm{Sr}$, any of these compounds adopt the monoclinic unit cell (space group $\mathrm{P} 2{ }_{1} / \mathrm{n}$ ). The structural analysis show that the $\mathrm{Ln}$ and $\mathrm{Ru}$ ions are arranged in an alternating manner (NaCl-type). For $\mathrm{Ca}_{2} \mathrm{LnRuO}_{6}, \mathrm{X}$-ray diffraction measurements show that $\mathrm{Ca}^{2+}$ ions partially occupy the Bsite, i.e., $\mathrm{Ca}^{2+}$ and $\mathrm{Ln}^{3+}$ ions are partially disordered at the A-site and half of the $\mathrm{B}$-site of the perovskite $\mathrm{ABO}_{3}$, and that $\mathrm{Ca}^{2+} /$ $\mathrm{Ln}^{3+}$ and $\mathrm{Ru}^{5+}$ ions located at the $\mathrm{B}$ site are regularly ordered. ${ }^{27}$ ) Therefore, these compounds should be represented by $\mathrm{Ca}_{2-x} \operatorname{Ln}_{x}-$ $\left[\operatorname{Ln}_{1-x} \mathrm{Ca}_{x}\right] \mathrm{RuO}_{6}$. The ratio of the $\mathrm{Ln}^{3+}$ ion located at the A-site varies with its ionic radius, as shown in Fig. 4.

All the $\mathrm{A}_{2} \mathrm{LnRuO}_{6}$ compounds prepared in this study show an antiferromagnetic transitions at low temperatures. Figure 5 shows the antiferromagnetic transition temperature for $\mathrm{A}_{2} \mathrm{LnRuO}_{6}$

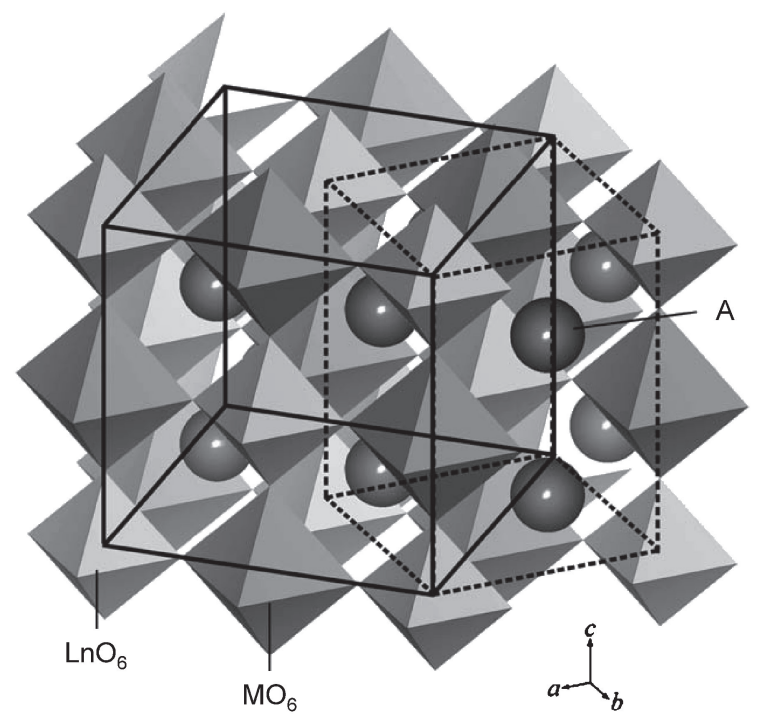

Fig. 3. The relationship between monoclinic and cubic double perovskites $\mathrm{A}_{2} \mathrm{LnMO}_{6}$. Solid and dotted lines show the cubic cell and the monoclinic cell, respectively.

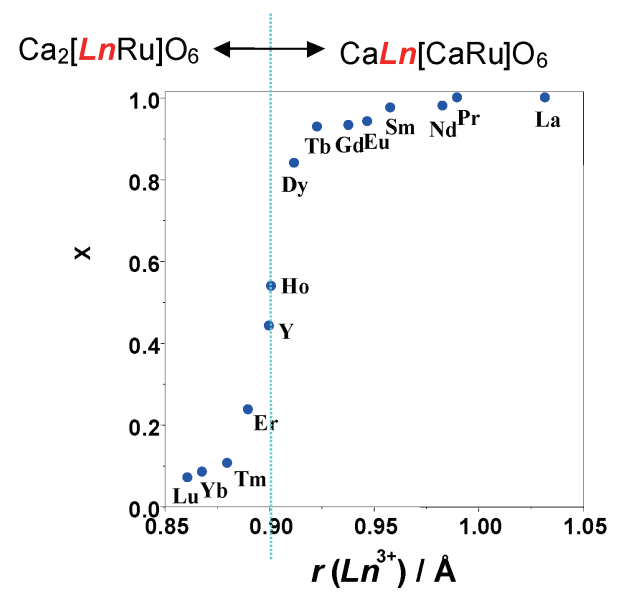

Fig. 4. The ratio of the $\mathrm{Ln}^{3+}$ ions at the A-site in the double perovskite $\mathrm{A}_{2} \operatorname{LnRuO}_{6}(x)$ against the $\mathrm{Ln}^{3+}$ radius. 


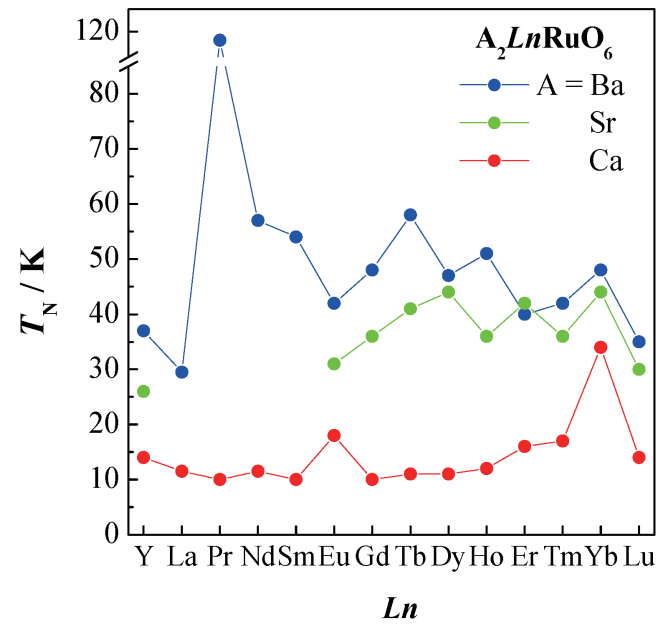

Fig. 5. The Néel temperatures $\left(T_{\mathrm{N}}\right)$ of $\mathrm{A}_{2} \mathrm{LnRuO}_{6}$.
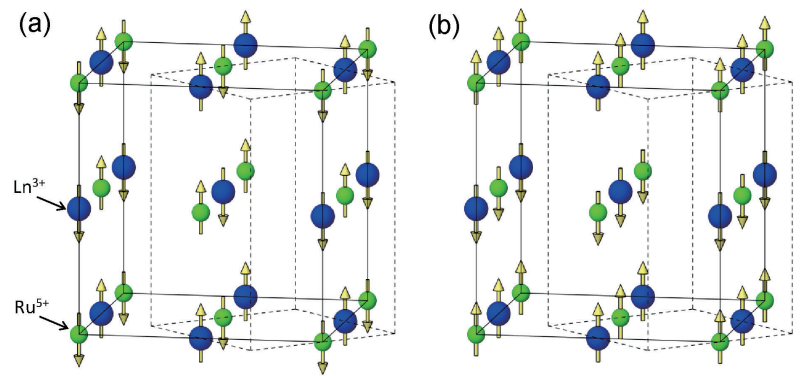

Fig. 6. Schematic magnetic structures of (a) $\mathrm{A}_{2} \mathrm{LnRuO}_{6}(\mathrm{Ln}=\mathrm{Tb}, \mathrm{Ho}$, Er, Tm) and (b) $\mathrm{A}_{2} \mathrm{LnRuO}_{6}(\mathrm{Ln}=\mathrm{Pr}, \mathrm{Nd}, \mathrm{Yb})$.

against the $\mathrm{Ln}$ (atomic number). For $\mathrm{A}=\mathrm{Ba}$ and $\mathrm{Sr}$ compounds, the Néel temperatures of the $\mathrm{A}_{2} \mathrm{LnRuO}_{6}(\mathrm{Ln} \neq \mathrm{Y}, \mathrm{La}, \mathrm{Eu})$ compounds are higher than those for $\mathrm{Ln}=\mathrm{Y}, \mathrm{La}, \mathrm{Eu}$ compounds. This fact indicates that the magnetic transition is mainly due to the magnetic cooperative phenomena between $\mathrm{Ru}^{5+}\left(4 \mathrm{~d}^{3}\right)$ and $\mathrm{Ln}^{3+}$ $\left(4 \mathrm{f}^{\mathrm{n}}\right)$ ions. When the A-site cation is changed from $\mathrm{Ba}$ to $\mathrm{Sr}$ to $\mathrm{Ca}$, the Néel temperature for $\mathrm{A}_{2} \mathrm{LnRuO}_{6}$ compounds decreases considerably. With decreasing the size of A-site cation, the alignment of $\mathrm{Ln}-\mathrm{O}-\mathrm{Ru}$ deviates from $180^{\circ}$, which results in weakening the magnetic super-exchange interaction between $\mathrm{f}$ and $\mathrm{d}$ electrons via oxygen atoms. In the case of $\mathrm{A}=\mathrm{Ca}$, the Néel temperatures for $\mathrm{Ln}=\mathrm{La}-\mathrm{Ho}$ compounds are nearly constant, which reflects the fact that the B-site cations are $\mathrm{Ru}$ and $\mathrm{Ca}$.

Neutron diffraction measurements show that the magnetic structures of these compounds are based on the type I ordering of $\mathrm{Ru}^{5+}$ and $\mathrm{Ln}^{3+}$ ions and schematic magnetic structures of $\mathrm{A}_{2} \mathrm{LnRuO}_{6}$ are shown in Fig. 6. The $\mathrm{A}_{2} \mathrm{LnRuO}_{6}(\mathrm{Ln}=\mathrm{Tb}, \mathrm{Ho}$, Er, Tm) compounds adopt the magnetic structure (a), while the $\mathrm{A}_{2} \mathrm{LnRuO}_{6}$ compounds with $\mathrm{Pr}, \mathrm{Nd}, \mathrm{Yb}$ adopt the structure (b). ${ }^{23)}$ The difference between these magnetic structures is in the arrangement of the magnetic moments of $\mathrm{Ln}^{3+}$ and $\mathrm{Ru}^{5+}$ ions in the $a b$ plane. For example, in the case of $\mathrm{Sr}_{2} \mathrm{TbRuO}_{6}$, the moments of $\mathrm{Ln}^{3+}$ and $\mathrm{Ru}^{5+}$ are antiparallel with each other, while they are parallel for $\mathrm{Ba}_{2} \mathrm{PrRuO}_{6}$. The magnetic structure data are summarized in Table 1.

\section{Triple perovskites $\mathrm{Ba}_{3} \mathrm{LnM}_{2} \mathrm{O}_{9}(\mathrm{M}=\mathrm{Ru})$}

Next, we paid our attention to the structure and magnetic properties of triple perovskite oxides containing rare earth and ruthenium, $\mathrm{Ba}_{3} \mathrm{LnRu}_{2} \mathrm{O}_{9}$.
Table 1. Summary of magnetic properties of $\mathrm{A}_{2} \mathrm{LnRuO}_{6}$

\begin{tabular}{ccccccc}
\hline $\mathrm{Ln}$ & $\mathrm{A}$ & Type $^{* 1}$ & $\begin{array}{c}\text { Direction of } \\
\text { magnetic } \\
\text { moments }\end{array}$ & $\mu(\mathrm{Ru}) / \mu_{\mathrm{B}}$ & $\mu(\mathrm{Ln}) / \mu_{\mathrm{B}}$ & $T_{\mathrm{N}}(\mathrm{K})$ \\
\hline $\mathrm{La}$ & $\mathrm{Ba}$ & $\mathrm{III}_{\mathrm{a}}$ & $c$-axis & 1.95 & - & 29.5 \\
$\mathrm{Pr}$ & $\mathrm{Ba}$ & $\mathrm{I}_{\mathrm{p}}$ & $c$-axis & 2.0 & 2.2 & 117 \\
$\mathrm{Nd}$ & $\mathrm{Ba}$ & $\mathrm{I}_{\mathrm{p}}$ & $a b$-plane & 2.2 & 2.3 & 57 \\
$\mathrm{~Tb}$ & $\mathrm{Sr}$ & $\mathrm{I}_{\mathrm{a}}$ & $c$-axis $20^{\circ}$ & 2.99 & 4.98 & 41 \\
& $\mathrm{Sr}$ & $\mathrm{I}_{\mathrm{a}}$ & $c$-axis & 2.71 & 6.68 & 36 \\
$\mathrm{Ho}$ & $\mathrm{Ba}$ & $\mathrm{I}_{\mathrm{a}}$ & $c$-axis & 2.9 & 9.7 & 51 \\
& $\mathrm{Sr}$ & $\mathrm{I}_{\mathrm{a}}$ & $a b$-plane & 2.74 & 4.59 & 42 \\
$\mathrm{Er}$ & $\mathrm{Ba}$ & $\mathrm{I}_{\mathrm{a}}$ & $a b$-plane & 2.9 & 4.3 & 40 \\
& $\mathrm{Sr}$ & $\mathrm{I}_{\mathrm{a}}$ & $c$-axis & 1.5 & 1.4 & 36 \\
$\mathrm{Tm}$ & $\mathrm{Ba}$ & $\mathrm{I}_{\mathrm{a}}$ & $c$-axis & 2.13 & 1.91 & 42 \\
& $\mathrm{Sr}$ & $\mathrm{I}_{\mathrm{p}}$ & $c$-axis $20^{\circ}$ & 3.0 & 0.92 & 44 \\
$\mathrm{Yb}$ & $\mathrm{Ba}$ & $\mathrm{I}_{\mathrm{p}}$ & $c$-axis $20^{\circ}$ & 2.57 & 1.00 & 48 \\
& $\mathrm{Sr}$ & $\mathrm{I}$ & $a b$-plane & 2.10 & - & 30 \\
$\mathrm{Lu}$ & $\mathrm{Ba}$ & $\mathrm{I}$ & $a b$-plane & 2.06 & - & 35 \\
& $\mathrm{Sr}$ & $\mathrm{I}$ & $a b$-plane & 1.85 & - & 26 \\
$\mathrm{Y}$ & $\mathrm{Ba}$ & $\mathrm{I}$ & $a b$-plane & 2.11 & - & 37 \\
\hline
\end{tabular}

Note: ${ }^{* 1} \mathrm{I}_{\mathrm{p}}$; parallel arrangement of magnetic moments between $\mathrm{Ln}$ and $\mathrm{Ru}$ ions in the $a b$ plane, $\mathrm{I}_{\mathrm{a}}$; antiferromagnetic arrangement.

Structures of perovskite oxides $\left(A B \mathrm{O}_{3}\right)$ can be regarded as the stacking of close-packed $A \mathrm{O}_{3}$ layers and the filling of subsequent octahedral sites by $B$-site ions. The difference in the stacking sequence changes the way of linkage of $\mathrm{BO}_{6}$ octahedra: the corner-sharing $\mathrm{BO}_{6}$ in the cubic perovskite (3L: three-layer) with $a b c \ldots$ sequence, the face-sharing $\mathrm{BO}_{6}$ in $2 \mathrm{~L}$-perovskite $(2 \mathrm{~L}$ : two-layer) with $a b \ldots$ sequence, and mixed linkages between the corner- and face-sharing in various intergrowth structures. ${ }^{28)}$ The stacking sequence is controlled by changing the ratio of the $L n$ and $M$ ions. Double perovskites $\mathrm{Ba}_{2} L n M \mathrm{O}_{6}$ (doubling the formula unit, Fig. 7, left) are formed, when the size and/or charge of the $L n$ and $M$ cations are sufficiently different and the ratio of $\operatorname{Ln}: \mathrm{M}=1: 1$.

When the ratio of $L n: M$ is $1: 2$, triple perovskites $\mathrm{Ba}_{3} L n M_{2} \mathrm{O}_{9}$ are formed. Ln and $\mathrm{Ru}$ ions occupy the corner-sharing and facesharing sites, respectively, and form the $\mathrm{LnO}_{6}$ octahedron and the $\mathrm{Ru}_{2} \mathrm{O}_{9}$ polyhedron. This $\mathrm{Ru}_{2} \mathrm{O}_{9}$ polyhedron consists of two facesharing $\mathrm{RuO}_{6}$ octahedra $\left(\mathrm{Ru}_{2} \mathrm{O}_{9}\right.$ dimer ${ }^{29)}$ (Fig. 7, middle). The magnetic behavior of this $\mathrm{Ru}_{2} \mathrm{O}_{9}$ dimer is attractive because of a very short $\mathrm{Ru}-\mathrm{Ru}$ distance $(2.5-2.7 \mathrm{~A})$ in the dimer. Therefore, one expects to find a strong magnetic interaction between $\mathrm{Ru}$ ions in the dimer.

From the analysis of the lattice parameters and bond lengths for $\mathrm{Ba}_{3} \mathrm{LnRu}_{2} \mathrm{O}_{9}$, the oxidation state of both $\mathrm{Ru}$ and $\mathrm{Ln}$ ions is tetravalent for the $\mathrm{Ce}, \mathrm{Pr}$, and $\mathrm{Tb}$ compounds, i.e., $\mathrm{Ba}_{3} \mathrm{Ln}^{4+}$ $\mathrm{Ru}^{4+}{ }_{2} \mathrm{O}_{9}{ }^{30)}$ On the other hand, the other compounds adopt a valence configuration of $\mathrm{Ba}_{3} \mathrm{Ln}^{3+} \mathrm{Ru}^{4.5+}{ }_{2} \mathrm{O}_{9}$. Their magnetic properties change widely with $\mathrm{Ln}$ ion, and are summarized in Table 2. Two kinds of magnetic interactions are important in determining their magnetic properties. One is the magnetic interaction between two $\mathrm{Ru}$ ions in the $\mathrm{Ru}_{2} \mathrm{O}_{9}$ dimer; this brings about a strong antiferromagnetic coupling between the $\mathrm{Ru}$ ions, and the characteristic temperature-dependence of the magnetic susceptibilities (a broad maximum above $100 \mathrm{~K}$ ) is observed for $\mathrm{Ba}_{3} \mathrm{LnRu}_{2} \mathrm{O}_{9}$. Figures 8(a) and 8(b) show the magnetic susceptibility vs. temperature curves for $\mathrm{Ba}_{3} \mathrm{LnRu}_{2} \mathrm{O}_{9}(\mathrm{Ln}=\mathrm{Y}, \mathrm{Lu}, \mathrm{Pr})$. Another important interaction is the one between the $\mathrm{Ru}$ and $\mathrm{Ln}$ ions via the linear $\mathrm{Ru}-\mathrm{O}-\mathrm{Ln}$ pathway, which is in common with the case of double perovskites $\mathrm{A}_{2} \mathrm{LnRuO}_{6}$. The magnetic transition due to the magnetic ordering of $\mathrm{Ln}$ ions has been found 


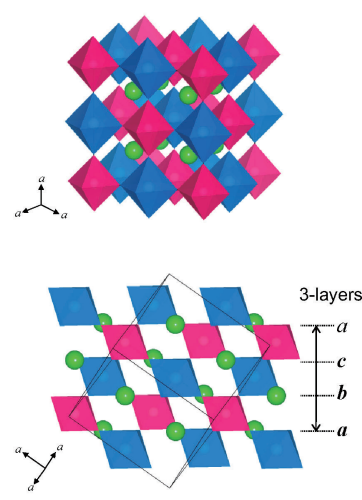

$n=2$

$\mathrm{A}_{2} \mathrm{LnMO}_{6}$

"double perovskite"

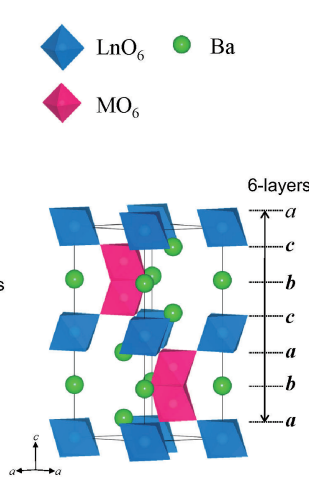

$n=3$

$6 \mathrm{~L}-\mathrm{Ba}_{3} \mathrm{LnM}_{2} \mathrm{O}_{9}$ "triple perovskite"

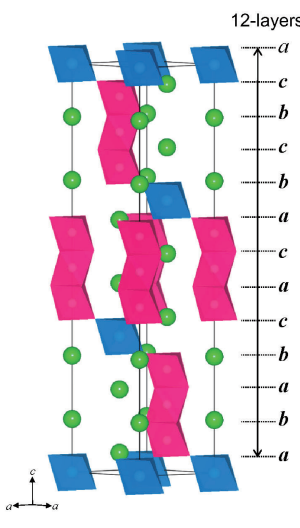

$n=4$

$12 \mathrm{~L}-\mathrm{Ba}_{4} \mathrm{LnM}_{3} \mathrm{O}_{12}$

"quadruple perovskite"

Fig. 7. Crystal structures of $A_{n} L_{n-1} O_{3 n}(A=C a, S r, B a ; M=R u, I r ; n=2-4)$.

Table 2. Summary of magnetic properties of $6 \mathrm{~L}-\mathrm{Ba}_{3} \mathrm{LnRu}_{2} \mathrm{O}_{9}$

\begin{tabular}{ccccc}
\hline $\mathrm{Ln}$ & Oxidation state of $\mathrm{Ln}$ & $T_{\mathrm{a}}(\mathrm{K})^{{ }^{*} 1}$ & $T_{\mathrm{b}}(\mathrm{K})^{*_{2}}$ & Neutron diffraction measurements \\
\hline $\mathrm{Y}$ & +3 & 290 & $4.5(\mathrm{AF})$ & - \\
$\mathrm{La}$ & +3 & 22 & $6.0(\mathrm{AF})$ & - \\
$\mathrm{Ce}$ & +4 & $>400$ & - & - \\
$\mathrm{Pr}$ & +4 & 380 & $10.5(\mathrm{AF})$ & - \\
$\mathrm{Nd}$ & +3 & - & $24.0(\mathrm{~F})$ & Ferromagnetic ordering of $\mathrm{Nd}^{3+}, 1.65 \mu_{\mathrm{B}} / \mathrm{Nd}(\mathrm{at} 10 \mathrm{~K})$ \\
$\mathrm{Sm}$ & +3 & 180 & $12.5(\mathrm{AF})$ & - \\
$\mathrm{Eu}$ & +3 & 135 & $9.5(\mathrm{AF})$ & - \\
$\mathrm{Gd}$ & +3 & - & $14.8(\mathrm{AF})$ & - \\
$\mathrm{Tb}$ & +4 & - & $9.5(\mathrm{AF})$ & Antiferromagnetic ordering of $\mathrm{Tb}^{4+}, 6.84 \mu_{\mathrm{B}} / \mathrm{Tb}(\mathrm{at} 2.0 \mathrm{~K})$ \\
$\mathrm{Dy}$ & +3 & - & $27.8(\mathrm{AF})$ & - \\
$\mathrm{Ho}$ & +3 & - & $10.2(\mathrm{AF})$ & - \\
$\mathrm{Er}$ & +3 & - & $8.3(\mathrm{AF})$ & - \\
$\mathrm{Tm}$ & +3 & & $4.5(\mathrm{AF})$ & - \\
$\mathrm{Yb}$ & +3 & 345 & $9.5(\mathrm{AF})$ & - \\
$\mathrm{Lu}$ & +3 & & & - \\
\hline
\end{tabular}

Note: ${ }^{*}$; Temperatures at which a broad maximum was observed in the $\chi$ vs $\mathrm{T}$ curves due to the magnetic ordering ${ }$ of $\mathrm{Ru}_{2} \mathrm{O}_{9}$ dimer, ${ }^{*}$; magnetic ordering of $\mathrm{Ln}$ ions.

(a)

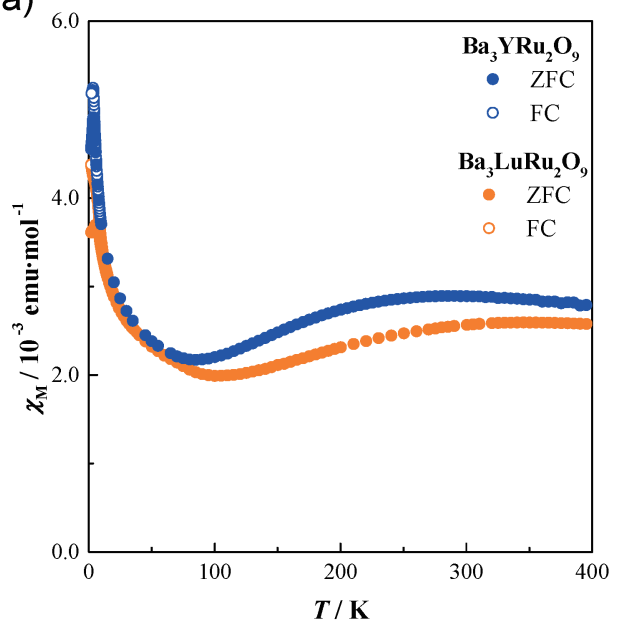

(b)

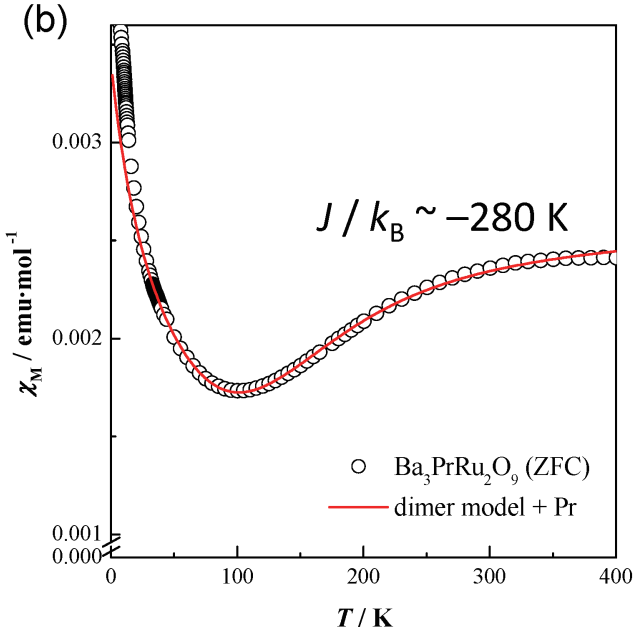

Fig. 8. Temperature dependence of the magnetic susceptibility for (a) $\mathrm{Ba}_{3} \mathrm{LnRu}_{2} \mathrm{O}_{9}(\mathrm{Ln}=\mathrm{Y}, \mathrm{Lu})$ and (b) $\mathrm{Ba}_{3} \operatorname{PrRu}_{2} \mathrm{O}_{9}$.

in the $\mathrm{Ba}_{3} \mathrm{LnRu}_{2} \mathrm{O}_{9}$ compounds ( $\mathrm{Ln}=$ magnetic ions) below $10 \mathrm{~K}^{31)}$ Figure 9 shows the temperature dependence of the magnetic susceptibility and specific heat for $\mathrm{Ba}_{3} \mathrm{TbRu}_{2} \mathrm{O}_{9}$, and Fig. 10 depicts its magnetic structure determined at $2.0 \mathrm{~K}$.

\section{Quadruple perovskites $\mathrm{Ba}_{4} \mathrm{LnM}_{3} \mathrm{O}_{12}(\mathrm{M}=\mathrm{Ru}, \mathrm{Ir})$}

In the $\mathrm{Ba}_{3} L n M_{2} \mathrm{O}_{9}$, the ground state of the total spin of the isolated $M_{2} \mathrm{O}_{9}$ dimer may be zero, i.e., $S_{\text {dimer }}=S_{1}+S_{2}=0$, for 

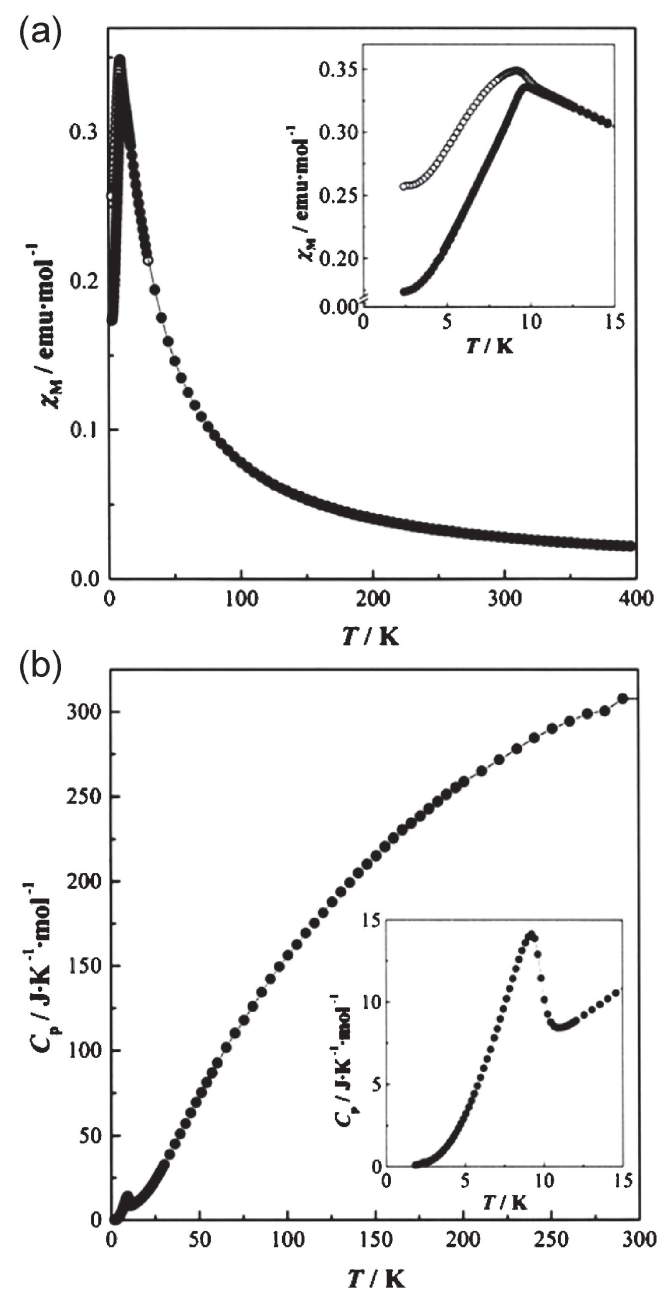

Fig. 9. Temperature dependence of (a) magnetic susceptibility and (b) specific heat for $\mathrm{Ba}_{3} \mathrm{TbRu}_{2} \mathrm{O}_{9}$.

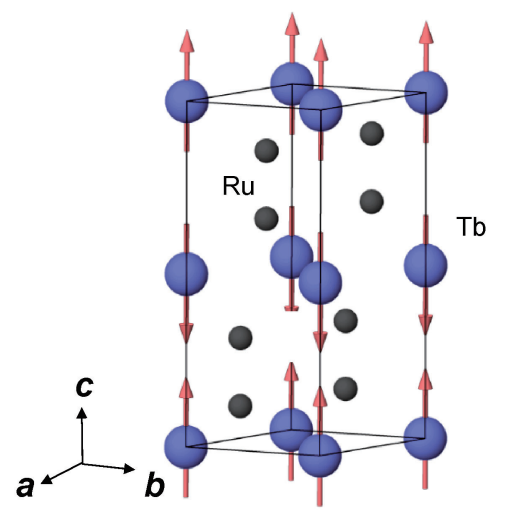

Fig. 10. Magnetic structure of $\mathrm{Ba}_{3} \mathrm{TbRu}_{2} \mathrm{O}_{9}$ at $2.0 \mathrm{~K}$.

the case that the antiferromagnetic coupling exists between the $\mathrm{M}$ ions.

Then, we started studies on quadruple perovskites $\mathrm{Ba}_{4} \operatorname{LnM} M_{3} \mathrm{O}_{12}$ in which the ratio of $L n: M$ is $1: 3$. Three $M \mathrm{O}_{6}$ octahedra are connected to each other by face-sharing and form a $M_{3} \mathrm{O}_{12}$ trimer. The $M_{3} \mathrm{O}_{12}$ trimers and $L n \mathrm{O}_{6}$ octahedra are alternately linked by corner-sharing (Fig. 7, right). As shown in this figure, the perovskite-type structure with 12 layers is formed (the stacking sequence: $a b a b c a c a b c b c \ldots .{ }^{32)-36)}$ In this case, the total magnetic

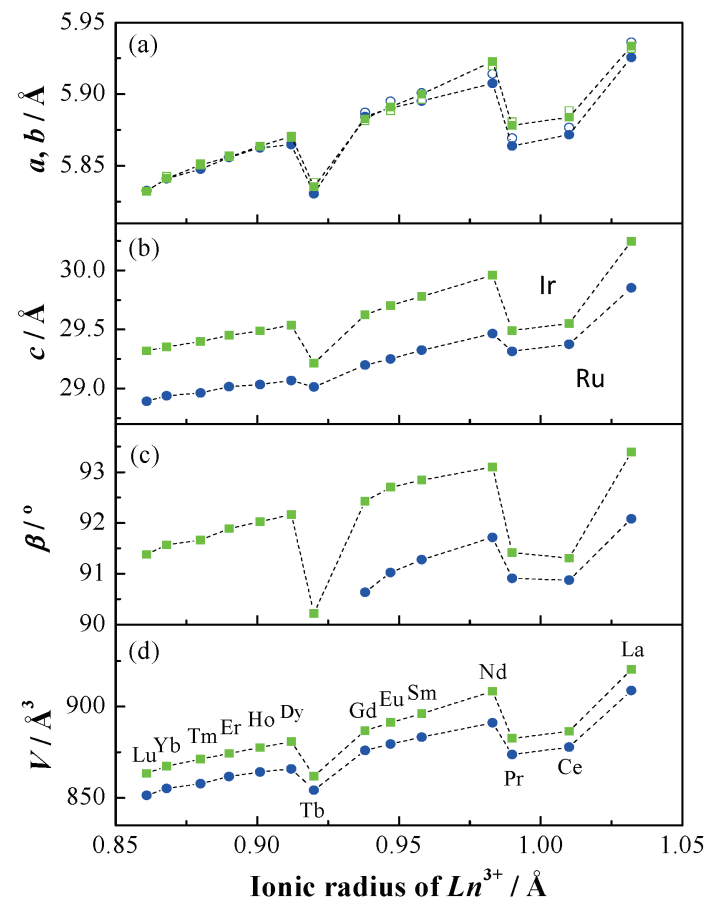

Fig. 11. Variation of lattice parameters and volumes for $\mathrm{Ba}_{4} \mathrm{LnM}_{3} \mathrm{O}_{12}$ $\left(\mathrm{M}=\mathrm{Ru}\right.$, Ir) with $\mathrm{Ln}^{3+}$ radius.

moment of the $M_{3} \mathrm{O}_{12}$ trimer does not disappear as far as three $M$ ions are equivalent in the trimer (i.e., $S_{\text {trimer }}=S_{1}+S_{2}+S_{3} \neq 0$ ), and the ground state of the total spin of the $M_{3} \mathrm{O}_{12}$ trimer should strongly contribute to the magnetic properties of $\mathrm{Ba}_{4} L n M_{3} \mathrm{O}_{12}$.

Quadruple perovskites $\mathrm{Ba}_{4} L n M_{3} \mathrm{O}_{12}(L n=\mathrm{La}-\mathrm{Nd}, \mathrm{Sm}-\mathrm{Lu}$; $M=\mathrm{Ru}, \mathrm{Ir}$ ) were prepared as a single phase. The powder X-ray diffraction measurements and their Rietveld analysis show that the $\mathrm{Ba}_{4} L n \mathrm{Ru}_{3} \mathrm{O}_{12}$ compounds for $L n=\mathrm{Tb}-\mathrm{Lu}$ have a hexagonal unit cell with space group $R-3 m$ (No.166), while those for $\mathrm{Ln}=\mathrm{La}-\mathrm{Nd}, \mathrm{Sm}-\mathrm{Gd}$ have a monoclinic unit cell with space group $C 2 / m$ (No.12) due to the larger difference in the ionic radius between $L n$ and $\mathrm{Ru}^{35)}$ On the other hand, all the iridium compounds $\mathrm{Ba}_{4} L n \mathrm{Ir}_{3} \mathrm{O}_{12}$ were indexed with the monoclinic unit cell. The $M-M$ interatomic distances in the $M_{3} \mathrm{O}_{12}$ trimer are 2.4$2.6 \AA$ for both $\mathrm{Ba}_{4} L n \mathrm{Ru}_{3} \mathrm{O}_{12}$ and $\mathrm{Ba}_{4} L n \mathrm{Ir}_{3} \mathrm{O}_{12}$ compounds. These distances are much shorter than double the metallic radius of $\mathrm{Ru}$ and $\operatorname{Ir}(2.72 \AA),{ }^{37)}$ indicating that strong interactions between $M$ ions should exist in the $M_{3} \mathrm{O}_{12}$ trimer.

The lattice parameters and volumes of $\mathrm{Ba}_{4} L n M_{3} \mathrm{O}_{12}$ were plotted against the ionic radius of $\mathrm{Ln}^{3+}$ in Fig. 11. Except for the compounds having $L n=\mathrm{Ce}, \mathrm{Pr}$, and $\mathrm{Tb}$, the lattice parameters $a, b, c$, and $\beta$ monotonously increase with the $\mathrm{Ln}^{3+}$ ionic radius. However, the values for $L n=\mathrm{Ce}, \mathrm{Pr}$, and $\mathrm{Tb}$ compounds are considerably smaller than this trend. The $\mathrm{Ln}-\mathrm{O}$ bond lengths are close to the $L n^{4+}-\mathrm{O}^{2-}$ lengths calculated from Shannon's ionic radii. ${ }^{38)}$ These results show that the $\mathrm{Ce}, \mathrm{Pr}$, and $\mathrm{Tb}$ ions are in the tetravalent state. Therefore, the oxidation states of $\mathrm{Ru}$ and $\mathrm{Ir}$ are also tetravalent $\left(\mathrm{Ba}_{4} L n^{4+} \mathrm{Ru}^{4+}{ }_{3} \mathrm{O}_{12}, \mathrm{Ba}_{4} L n^{4+} \mathrm{Ir}^{4+}{ }_{3} \mathrm{O}_{12}\right)$. For other $\mathrm{Ln}$ ions, the mean oxidation state of $\mathrm{Ru}$ and $\mathrm{Ir}$ ions is +4.33 $\left.\left(\mathrm{Ba}_{4} L n^{3+} \mathrm{Ru}^{4.33+}{ }_{3} \mathrm{O}_{12}, \mathrm{Ba}_{4} L n^{3+} \mathrm{Ir}^{4.33+}{ }_{3} \mathrm{O}_{12}\right) \cdot{ }^{39), 40}\right)$

\subsection{Magnetic properties of $\mathrm{Ba}_{4} \mathrm{Ln}^{3+} \mathrm{M}^{4.33+}{ }_{3} \mathrm{O}_{12}$}

Measurements of the magnetic susceptibility for $\mathrm{Ba}_{4} \operatorname{LnM} M_{3} \mathrm{O}_{12}$ give the contrastive results between the ruthenium-containing

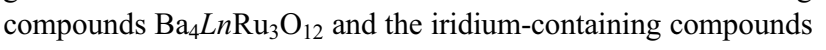
$\mathrm{Ba}_{4} \operatorname{Ln} \mathrm{Ir}_{3} \mathrm{O}_{12}$, and the results are summarized in Table 3. Any of 


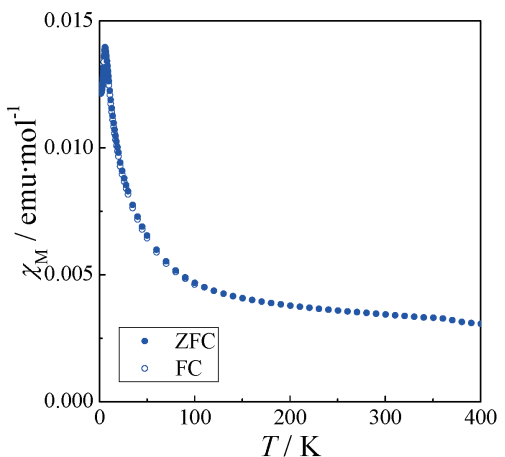

Fig. 13. Temperature dependence of the magnetic susceptibility for $\mathrm{Ba}_{4} \mathrm{LaRu}_{3} \mathrm{O}_{12}$.

The highest occupied $e_{\mathrm{u}}$ orbital has the $S=1 / 2$ ground state. Therefore, the $\mathrm{Ru}^{4.33+}{ }_{3} \mathrm{O}_{12}$ trimer $\left(S_{\text {trimer }}=1 / 2\right)$ contributes to the magnetic properties of $\mathrm{Ba}_{4} \mathrm{LnRu}_{3} \mathrm{O}_{12}$. Figure 13 shows the temperature dependence of the magnetic susceptibility for $\mathrm{Ba}_{4} \mathrm{LaRu}_{3}-$ $\mathrm{O}_{12}$. Both $\mathrm{Ba}_{4} \mathrm{LaRu}_{3} \mathrm{O}_{12}$ and $\mathrm{Ba}_{4} \mathrm{LuRu}_{3} \mathrm{O}_{12}$ order antiferromagnetically at 6.0 , and $8.0 \mathrm{~K}$, respectively. Since $\mathrm{La}^{3+}$ and $\mathrm{Lu}^{3+}$ ions are diamagnetic, the $\mathrm{Ru}^{4.33+}{ }_{3} \mathrm{O}_{12}$ trimers are antiferromagnetically coupled. Other $\mathrm{Ba}_{4} L n \mathrm{Ru}_{3} \mathrm{O}_{12}$ compounds show similar antiferromagnetic transitions at comparable temperatures, which should be due to the magnetic ordering of the $\mathrm{Ru}^{4.33+}{ }_{3} \mathrm{O}_{12}$ trimers.

\subsection{Magnetic properties of $\mathrm{Ba}_{4} \mathrm{Ln}^{4+} \mathrm{M}^{4+}{ }_{3} \mathrm{O}_{12}$}

Table 3 shows that the magnetic behavior is contrastive between two compounds $\mathrm{Ba}_{4} \mathrm{Ce}_{3} \mathrm{O}_{12}(M=\mathrm{Ru}$, Ir), i.e., the iridium-containing compound $\mathrm{Ba}_{4} \mathrm{CeIr}_{3} \mathrm{O}_{12}$ antiferromagnetically orders at $10.5 \mathrm{~K}$, while the ruthenium-containing compound $\mathrm{Ba}_{4}-$ $\mathrm{CeRu}_{3} \mathrm{O}_{12}$ shows no magnetic ordering down to $0.5 \mathrm{~K}$. Since the tetravalent $\mathrm{Ce}^{4+}$ ion is diamagnetic, only the $M^{4+}$ ions (i.e., $\mathrm{Ru}^{4+}$ and $\mathrm{Ir}^{4+}$ ions) contribute to the magnetic properties of $\mathrm{Ba}_{4}$ $\mathrm{Ce}_{3} \mathrm{O}_{12}$ compounds, and this magnetic behavior of $\mathrm{Ba}_{4} L n^{4+}$. $\mathrm{M}^{4+}{ }_{3} \mathrm{O}_{12}$ is understandable by considering the magnetic properties of $M^{4+}{ }_{3} \mathrm{O}_{12}$ trimer.

In the same way as the case of $\operatorname{Ir}^{4.33+}{ }_{3} \mathrm{O}_{12}$, the $\mathrm{Ir}^{4+}{ }_{3} \mathrm{O}_{12}$ trimer has fifteen $5 d$ electrons, and its electron configuration is $\left(a_{1 \mathrm{~g}}\right)^{2}\left(e_{\mathrm{g}}\right)^{4}\left(a_{2 \mathrm{u}}\right)^{2}\left(e_{\mathrm{u}}\right)^{4}\left(e_{\mathrm{g}}\right)^{3}$ [see Fig. 12(d)]. The highest occupied $e_{\mathrm{g}}$ orbitals (doublet) have the $S=1 / 2$ ground state. The antiferromagnetic ordering of $\mathrm{Ba}_{4} \mathrm{CeIr}_{3} \mathrm{O}_{12}$ is due to this ground $S=1 / 2$ state. On the other hand, the electron configuration of the $\mathrm{Ru}_{3}^{4+} \mathrm{O}_{12}$ trimer is $\left(a_{1 \mathrm{~g}}\right)^{2}\left(e_{\mathrm{g}}\right)^{4}\left(a_{2 \mathrm{u}}\right)^{2}\left(e_{\mathrm{u}}\right)^{4}$, indicating the $S=0$ ground state of the filled HOMO, as shown in Fig. 12(b). Therefore, $\mathrm{Ba}_{4} \mathrm{CeRu}_{3} \mathrm{O}_{12}$ should be diamagnetic and shows no magnetic ordering. Actually it is weakly paramagnetic, indicating that the molecular orbital model is not perfect for the case of $\mathrm{Ru}_{3} \mathrm{O}_{12}$ trimer. We have to consider the excited state. This is because the $4 d$ electrons are somewhat more localized than the $5 d$ electrons. ${ }^{42)}$

As listed in Table 3, magnetic susceptibility measurements for $\mathrm{Ba}_{4} \mathrm{PrRu}_{3} \mathrm{O}_{12}$ and $\mathrm{Ba}_{4} \operatorname{PrIr}_{3} \mathrm{O}_{12}$ show that an antiferromagnetic transition occurs at 2.4 and $35 \mathrm{~K}$, respectively. Since $\mathrm{Ba}_{4} \mathrm{CeRu}_{3}-$ $\mathrm{O}_{12}$ shows no long-range magnetic ordering down to $0.5 \mathrm{~K}$, the magnetic anomaly observed at $2.4 \mathrm{~K}$ in $\mathrm{Ba}_{4} \mathrm{PrRu}_{3} \mathrm{O}_{12}$ is due to the magnetic interactions of the magnetic moment of $\mathrm{Pr}^{4+}$ ions. The results of the specific heat measurements and evaluation of the magnetic entropy change due to the antiferromagnetic ordering have quantitatively cleared this point. ${ }^{35)}$

Figure 14 illustrates that the magnetic structure of $\mathrm{Ba}_{4} \mathrm{TbRu}_{3}$ $\mathrm{O}_{12}$ at $2.5 \mathrm{~K}$. The magnetic moments of $\mathrm{Tb}$ and $\mathrm{Ru}$ ions are

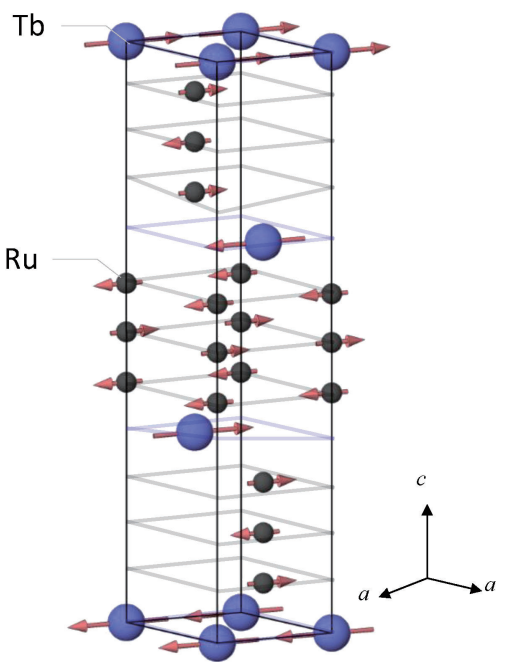

Fig. 14. Magnetic structure of $\mathrm{Ba}_{4} \mathrm{TbRu}_{3} \mathrm{O}_{12}$ at $2.5 \mathrm{~K}$.

collinear and lie on the $a b$ plane. The $\mathrm{Ru}$ moments in the $\mathrm{Ru}_{3} \mathrm{O}_{12}$ trimer order ferrimagnetically. Along the $c$-axis, each of the magnetic moments for $\mathrm{Tb}$ and $\mathrm{Ru}$ ions are alternately stacked. ${ }^{35)}$

\section{Summary}

Structures and magnetic properties of the general formula $\mathrm{A}_{\mathrm{n}} \mathrm{LnM}_{\mathrm{n}-1} \mathrm{O}_{3 \mathrm{n}}(\mathrm{A}=$ alkaline earth elements; $\mathrm{Ln}=$ rare earths; $\mathrm{M}=\mathrm{Ru}, \mathrm{Ir} ; \mathrm{n}=1-4$ ) have been studied. For the double perovskites $\mathrm{ALnMO}_{6}$, antiferromagnetic transitions due to the magnetic cooperative phenomena between $\mathrm{d}$ and $\mathrm{f}$ electrons have been observed at relatively high temperatures. For $\mathrm{n}=3$, 6L-perovskite type compounds $\mathrm{Ba}_{3} \mathrm{LnM}_{2} \mathrm{O}_{9}$ are formed. Peculiar temperature-dependence of the magnetic susceptibility has been found, which is explained by the $\mathrm{d}-\mathrm{f}$ magnetic interactions and the magnetic coupling between $\mathrm{M}$ ions in the $\mathrm{M}_{2} \mathrm{O}_{9}$ dimer. For $\mathrm{n}=4$, quadruple perovskites $\mathrm{Ba}_{4} \mathrm{LnM}_{3} \mathrm{O}_{12}$ with 12 layers are formed, in which $\mathrm{M}_{3} \mathrm{O}_{12}$ trimer and $\mathrm{LnO}_{6}$ octahedra are alternately linked by corner-sharing. Their magnetic behavior has been well explained by the number of $\mathrm{d}$ electrons in the $\mathrm{M}_{3} \mathrm{O}_{12}$ trimer and magnetic properties of Ln ions.

\section{References}

1) K. Ito, K. Tezuka and Y. Hinatsu, J. Solid State Chem., 157, 173-179 (2001).

2) A. J. Jacobson, B. C. Tofield and B. E. F. Fender, Acta Crystallogr., Sect. B: Struct. Crystallogr. Cryst. Chem., 28, 956-961 (1972).

3) B. C. Tofield, A. J. Jacobson and B. E. F. Fender, J. Phys., C, 5, 2887-2895 (1972).

4) Y. Hinatsu, M. Ito and N. Edelstein, J. Solid State Chem., 132, 337-341 (1997).

5) K. Tezuka, Y. Hinatsu, Y. Shimojo and Y. Morii, J. Phys.: Condens. Matter, 10, 11703-11712 (1998).

6) Y. Hinatsu and N. Edelstein, J. Solid State Chem., 112, 53-57 (1994).

7) Y. Hinatsu, J. Solid State Chem., 100, 136-140 (1992).

8) M. Bickel, G. L. Goodman, L. Soderholm and B. Kanellakopulos, J. Solid State Chem., 76, 178-185 (1988).

9) P. D. Battle, J. B. Goodenough and R. Price, J. Solid State Chem., 46, 234-244 (1983).

10) P. D. Battle and W. J. Macklin, J. Solid State Chem., 52, 138145 (1984)

11) P. D. Battle and C. W. Jones, J. Solid State Chem., 78, 108-116 (1989). 
12) P. D. Battle, C. W. Jones and F. Studer, J. Solid State Chem., 90, 302-312 (1991).

13) Y. Doi and Y. Hinatsu, J. Phys.: Condens. Matter, 11, 48134820 (1999).

14) M. Wakeshima, D. Harada and Y. Hinatsu, J. Alloys Compd., 287, 130-136 (1999).

15) D. Harada, M. Wakeshima and Y. Hinatsu, J. Solid State Chem., 145, 356-360 (1999).

16) M. Wakeshima, D. Harada and Y. Hinatsu, J. Solid State Chem., 147, 618-623 (1999).

17) Y. Doi, Y. Hinatsu, K. Oikawa, Y. Shimojo and Y. Morii, J. Mater. Chem., 10, 797-800 (2000).

18) Y. Izumiyama, Y. Doi, M. Wakeshima, Y. Hinatsu, K. Oikawa, Y. Shimojo and Y. Morii, J. Mater. Chem., 10, 2364-2367 (2000).

19) M. Wakeshima, D. Harada and Y. Hinatsu, J. Mater. Chem., 10, 419-422 (2000).

20) Y. Izumiyama, Y. Doi, M. Wakeshima, Y. Hinatsu, Y. Shimojo and Y. Morii, J. Phys.: Condens. Matter, 13, 1303-1313 (2001).

21) Y. Sasaki, Y. Doi and Y. Hinatsu, J. Mater. Chem., 12, 23612366 (2002).

22) Y. Izumiyama, Y. Doi, M. Wakeshima, Y. Hinatsu, A. Nakamura and Y. Ishii, J. Solid State Chem., 169, 125-130 (2002).

23) Y. Doi, Y. Hinatsu, A. Nakamura, Y. Ishii and Y. Morii, J. Mater. Chem., 13, 1758-1763 (2003).

24) K. Yamamura, M. Wakeshima and Y. Hinatsu, J. Solid State Chem., 179, 605-612 (2006).

25) R. Saez-Puche, E. Climent-Pascual, R. Ruiz-Bustos, M. A. Alario-Franco and M. T. Fernandez-Diaz, Prog. Solid State Chem., 35, 211-219 (2007).

26) M. Wakeshima, Y. Hinatsu and K. Ohoyama, J. Solid State Chem., 197, 236-241 (2013).
27) C. Sakai, Y. Doi and Y. Hinatsu, J. Alloys Compd., 408, 608612 (2006).

28) J. M. Longo and J. A. Kafalas, J. Solid State Chem., 1, 103108 (1969)

29) Y. Doi, K. Matsuhira and Y. Hinatsu, J. Solid State Chem., 165, 317-323 (2002).

30) Y. Doi, M. Wakeshima, Y. Hinatsu, A. Tobo, K. Ohoyama and Y. Yamaguchi, J. Mater. Chem., 11, 3135-3140 (2001).

31) Y. Doi, Y. Hinatsu, Y. Shimojo and Y. Ishii, J. Solid State Chem., 161, 113-120 (2001).

32) C. H. De Vreugd, H. W. Zandbergen and D. J. W. IJdo, Acta Crystallogr., Sect. C: Cryst. Struct. Commun., 40, 1987-1989 (1984).

33) A. F. Fuentes, K. Boulahya and U. Amador, J. Solid State Chem., 177, 714-720 (2004).

34) N. Creon, C. Michel, M. Hervieu, A. Maignan and B. Raveau, Solid State Sci., 5, 243-248 (2003).

35) Y. Shimoda, Y. Doi, Y. Hinatsu, K. Ohoyama and Y. Yamaguchi, Chem. Mater., 20, 4512-4518 (2008).

36) Y. Shimoda, Y. Doi, M. Wakeshima and Y. Hinatsu, J. Solid State Chem., 182, 2873-2879 (2009).

37) A. F. Wells, "Structural Inorganic Chemistry", 5th Ed., Oxford Clarendon Press (1984).

38) R. D. Shannon, Acta Crystallogr., Sect. A: Found. Crystallogr., 32, 751-767 (1976).

39) Y. Shimoda, Y. Doi, M. Wakeshima and Y. Hinatsu, Inorg. Chem., 48, 2104-2110 (2009).

40) Y. Shimoda, Y. Doi, M. Wakeshima and Y. Hinatsu, J. Solid State Chem., 183, 33-40 (2010).

41) B. E. Bursten, F. A. Cotton and A. Fang, Inorg. Chem., 22, 2127-2133 (1983).

42) Y. Shimoda, Y. Doi, M. Wakeshima and Y. Hinatsu, J. Solid State Chem., 183, 1962-1969 (2010).

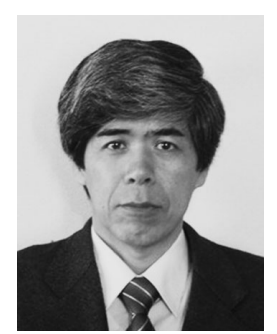

Yukio Hinatsu graduated from Osaka University in 1977 with a B.E. degree in nuclear engineering. $\mathrm{He}$ received his Ph. D. degree in nuclear engineering from Osaka University in 1982. After graduation, he joined the Japan Atomic Energy Research Institute as a Research Scientist. He studied the chemical behavior of fission products from the nuclear spent fuel at the Oak Ridge National Laboratory in Tennessee, USA, as a visiting scientist for one and half years in 1988-1989. Then, he moved to California and studied the electronic state of actinide ions in solids, at the Lawrence Berkeley Laboratory, University of California at Berkeley for a year in 1989-1990. Since 1995, he has been a full Professor of the Division of Chemistry, Faculty of Science, Hokkaido University. 